\title{
Acerca de algunos problemas del arte rupestre postpaleolítico en la Península Ibérica
}

\author{
E. Ripoll Perello *
}

El aun comúnmente llamado "arte levantino" fue descubierto en 1903 por Juan Cabré y Aguiló en el barranco de Calapatá (Cretas. Teruel). casi al mismo tiempo que lo era el abrigo de Cogul (Lérida) por el párroco R. Huguet y Ceferino Rocafort. Ambos lugares fueron inmediatamente estudiados por el abate Henri Breuil y su publicacion vio la luz en las páginas de L'Anthropologie. Luego los hallazgos prosiguieron a buen ritmo y en la actualidad se acerca al centenar el número de abrigos - de desigual importancia- con pinturas de este tipo. Por sus descubrimientos e investigaciones deben ser citados, despues del de aquéllos, los nombres de Eduardo Hernandez-Pacheco, Hugo Obermaier. Federico de Motos, Josep Colomines. Agusti Durán y Sanpere, Juan B. Porcar, Martín Almagro Basch. Francisco Jordá. Teógenes Ortego. Antonio Beltrán, M. A. Garcia Guinea, Javier Fortea, Martin Almagro Gorbea, Vicente Balde-

Catedrático de Prehistoria y Profesor Emerito de la UNED.- Este trabajo va dedicado a la memoria de mi entrañable amigo don Teogenes Ortego Frias. Su bibliografia ha sido reunida exhaustivamente por Juan A. Gomez BARRERA, «D. Teogenes Ortego Frias y su aportacion al estudio del arte rupestre postpaleolitico en la Peninsula lberica". Celtiberia (Soria). num. 75, 1988, pags. 47-77. al que nos remitimos y que nos excusa de las citas correspondientes en el apartado de bibliografia al final del presente trabajo. Originalmente texto de una conferencia. este articulo fue publicado aproximadamente con el mismo titulo en el librito Arte prehistorico de la provincia de Soria (Soria. Museo Numantino. 1990. pags. 79-92). Por contener algunas mutilaciones y gran número de erratas, se presenta de nuevo debidamente corregido y bastante ampliado, si bien conservando su caracter originario de disertación. 
llou. Ramón Viñas, F. Piñón Varela, Mauro S. Hernández, Ana Alonso y J. García del Toro, entre muchos otros.

Las pinturas de la facies levantina se hallan siempre en covachas y abrigos rocosos muy abiertos. Es decir, no se trata de un arte trogloditico como lo es generalmente el del Paleolítico superior. Para realizar las figuras levantinas, se utilizaron pigmentos minerales -rojo, negro y blanco en diferentes tonalidades, cuya naturaleza es indicada por los análisis espectograficos - y un excipiente organico desconocido, seguramente grasa animal o clara de huevo. Para su aplicación se usaron finos pinceles, seguramente fabricados con plumas de ave. La técnica empleada es casi siempre la "tinta plana" y. con menos frecuencia, la línea de contorno de la silueta y pequeños trazos en el interior. Por lo general, las figuras son de tamaño pequeño $(10 \mathrm{cms}$. de altura media, dejando de lado algunas grandes figuras de animales) y forman escenas o composiciones. En efecto, los artistas levantinos descubrieron la composición y, junto con ella, el movimiento con un gran sentido dinámico. Hay que atribuirles, asimismo, un concepto original de la figura humana, sujeto principal de las escenas representadas. En alguna rara ocasion hay figuras que tienen la silueta total o parcialmente grabada. Representaciones obtenidas por piqueteado sobre la superficie de la roca, que se encuentran en el área levantina, son, con seguridad, de la posterior facies esquemática, al igual que ciertas pinturas de las que hablaremos.

Las representaciones zoomorfas levantinas corresponden siempre a especies vivientes en un clima templado análogo al actual, siendo las más abundantes los toros, ciervos y caprinos. En la fase más antigua, se presentan de forma estática y aislada, muy naturalista. Luego se estilizan, van ganando dinamismo y se pasa a la agrupación en escenas. En las venatorias abundan las largas hileras de las huellas de los animales. Esta es la facies levantina clásica. Más tarde, por un progresivo ahorro de los detalles, de la estilización se pasa al esquematismo.

La imagen humana se representa siempre de una forma estilizada característica, con un vigor y sentido del movimiento sorprendentes. Los hombres van armados con arcos y flechas, llevan gorros o penachos y otros adornos y visten una especie de zaragüelles, seguramente unos pantalones de cuero anudados debajo de las rodillas, que servían para protegerse de la vegetación espinosa de las montañas en las que practicaban su actividad venatoria (fig. 1). En las escenas de guerra los hombres van desnudos. Las mujeres aparecen con el pecho al descubierto y faldas acampanadas muy largas (comunes en las representaciones femeninas del neolítico mediterráneo). Las escenas son principalmente cinegéticas, aunque las hay que reflejan actividades sociales tan extremas 


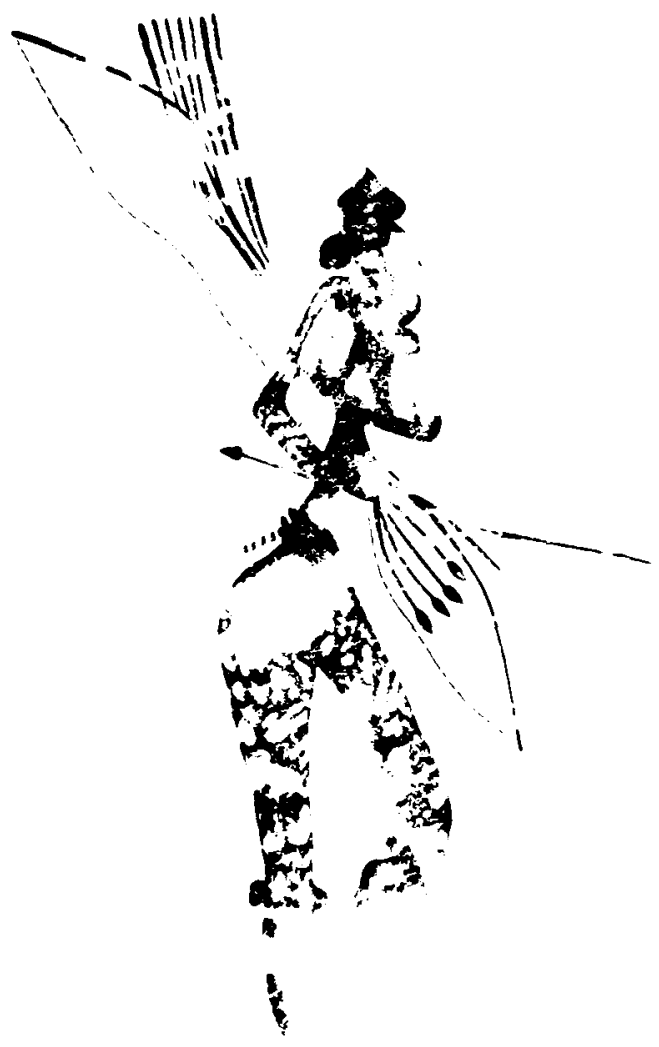

Fig. 1. Arquero que da su nombre al abrigo pintado de Ladruñán-Santolea (Teruel). (Según E. Ripoll, 1968).

como danzas, ejecuciones e incluso pequeños combates entre dos grupos de contendientes. Con seguridad todas estas pinturas tenían un valor recordatorio o conmemorativo, de grandes cacerias o de acontecimientos de la vida tribal.

Por tanto, en la interpretación del significado del arte levantino, aunque no se puede descartar por completo un factor mágico-religioso (que tan evidente es en el arte paleolítico), parece muy claro que estamos ante unas representaciones de amplio sentido conmemorativo y narrativo -acaso con el carácter de una especie de ex-votos-. Las pinturas nos informan sobre una sociedad de cazadores, cuya vida ilustran con gran riqueza, y en la que sólo se rastrean algunos rasgos "neolíticos". 
El arte levantino se extiende desde las provincias de Huesca y Lerida hasta la de Almeria, y penetra. hacia el interior. hasta las serranias de Cuenca-Teruel y la provincia de Albacete. En aquelia zona septentrional se están estudiando los magnificos hallazgos oscenses del rio Vero (Fuente del Trucho. Arpal, etc.). obra de V. Baldellou y su equipo. Sus cavidades contienen representaciones paleolíticas. levantinas y esquemáticas, que ayudan a comprender ciertos problemas cronologicos y de secuencia iconografica.

En la provincia de Lérida hay varios lugares de importancia menor. pero destaca el notable abrigo de Cogul. con la curiosa "escena". entre muchas otras figuras, de varias mujeres por parejas bailando alrededor de un sátiro (pero las mujeres fueron pintadas en momentos sucesivos y la figura del hombre es sin duda lo más moderno de la composición y. por tanto. la interpretación como danza ritual es muy insegura) (fig. 2). En la periferia del panel hay varias representaciones claramente esquemáticas $y$. cubriendolo todo. inscripciones grabadas en escritura ibérica y latina arcaica. que demuestran que en el lugar se siguieron realizando algunos ritos hasta el comienzo de la romanización.

En el bajo curso del rio Ebro, sobre ambas margenes. se hallan los conjuntos de Tivissa. Perelló. Vandellós, Ulldecona (Serra de la Pietat) y La Cenia (El Polvorín). En el Bajo Aragón, entre otros, son dignos de mencion los dos núcleos de Alacón (El Mortero y Cerro Felio). los abrigos de Val del Charco del Agua Amarga (cerca de Alcañiz) y los varios de la zona de Santolea, asi como el de Alcaine, mutilado no hace muchos años.

En el Maestrazgo o Maestrat. el primer conjunto conocido fue el de Morella la Vella (cerca de la ciudad de Morella), con curiosas representaciones de aves o insectos y un grupo de guerreros danzando. Luego se descubrieron en esta comarca dos de los núcleos más importantes del arte levantino: La Gasulla y La Valltorta. Los once abrigos de La Gasulla (Ares del Maestrat) presentan movidas cacerias de jabalies. grupos de guerreros. un arquero atacado por un toro. un jinete con casco - sobre el que volveremos-. etc. Los numerosos abrigos (Cova dels Cavalls. La Saltadora, Cova del Civil, etc.) del barranco de La Vallorta (Tirig y Albocasser). presentan complejos grupos de figuras humanas. una impresionante - pero muy estropeada - escena de caza de ciervos al ojeo. un cazador herido, etc.

De particular relevancia es el grupo de abrigos pintados de la zona de Albarracin y Cuenca. En la primera de dichas comarcas, el gran arte naturalista - por ejemplo. La Cocinilla del Obispo- enlaza con el arte 

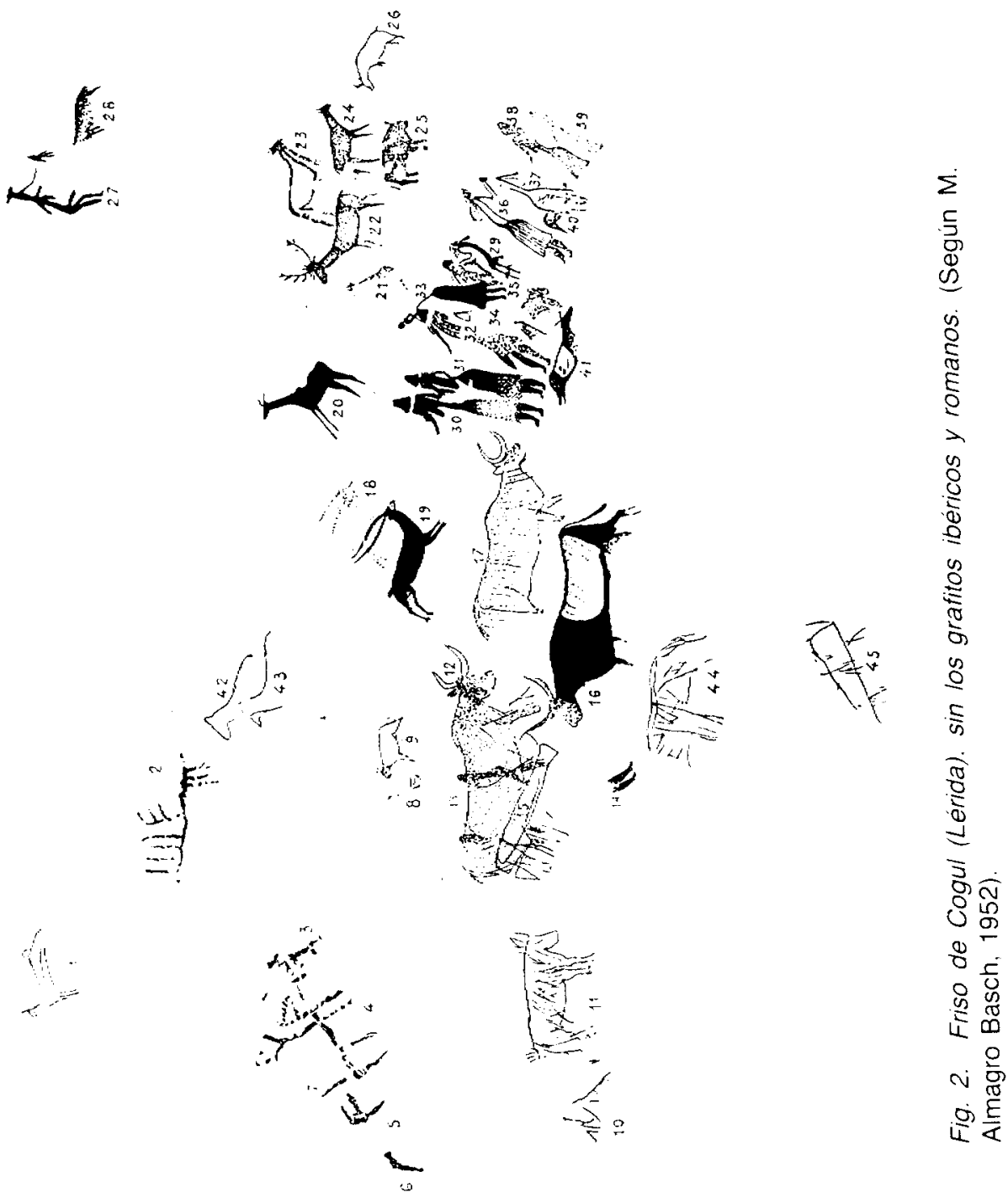
esquemático - covacho de Doña Clotilde-. Lo mismo sucede en Cuenca. En diversos abrigos de Albarracin abundan las figuras zoomorfas de color blanco, que destacan sobre la roca soporte rojiza del rodeno.

En Valencia, región muy rica en abrigos pintados, hay que mencionar el covacho de La Araña (Bicorp), en el que, junto a las consabidas cacerías, se pintó la conocida escena de la recolección de la miel, en la que una figura humana encaramada a una tosca escalera, con una bolsa en la mano, recoge la miel de una colmena silvestre (un agujero en la roca). En la provincia de Alicante se encuentran en el Plá de Petracós y regiones vecinas (sierras de Aitana, Mariola y Benicadell) las desconcertantes figuras del arte pictórico local denominado "macroesquemático" del que tendremos ocasión de hablar en estas mismas páginas. En el largo friso de La Sarga (Alcoy), hay bellas y realistas representaciones de ciervos superpuestas a grandes signos que seguramente tambien son de la facies macroesquemática con el anadido de una curiosa escena de recolección por vareo de los frutos de un árbol.

En la provincia de Albacete merecen ser destacados los conjuntos de Alpera y Minateda, y los numerosos abrigos de Nerpio y Moratalla. En el abrigo llamado Cueva de la Vieja (Alpera), en torno a un hombre de buen tamaño coronado por un gran penacho de plumas, se desarrollan una serie de escenas y figuras aisladas, llamando la atención unos toros que fueron repintados como ciervos, dos mujeres en amable coloquio y una caceria con la ayuda de perros. El gran friso de Minateda es un verdadero palimsesto, desgraciadamente muy estropeado, pero que fue minuciosamente calcado por el abate Breuil y posteriormente por $\mathrm{F}$. Benitez Mellado y que sirvió al primero para su teoría de la evolución estilística del arte levantino. En Nerpio, sobresalen los bellos ciervos de los abrigos de La Solana de las Covachas y otros en los que se observa la continuidad de las facies levantina y esquemática. En la provincia de Almeria hay pequeñas muestras de pinturas levantinas, aunque se inicia ahi el gran dominio andaluz de lo esquemático (cf. más adelante).

Para la cronologia relativa y evolución estilistica del arte levantino, el autor del presente texto elaboró en 1960 un sistema que aún es válido en sus lineas generales, aunque adolece sin duda de urı "evolucionismo" demasiado lineal. Justificado en trabajos nuestros citados en la bibliografia, en sintesis el sistema es el siguiente:

A. Fase naturalista: 1, período antiguo (toros de Albarracín); 2, período reciente (ciervos de Calapatá). 


\section{B. Fase estilizada estática. \\ C. Fase estilizada dinámica. \\ D. Fase de transición a la facies esquemática.}

Desde el punto de vista cronológico-cultural, A) correspondería a una población epipaleolítica de cazadores (6500 a 4000), B) y C) habrían vivido el contacto y la influencia - aculturación - de los primeros neolíticos del litoral, practicantes de la agricultura de azada y pequeña ganadería que iban penetrando hacia el interior; mientras que D) sería paraiela a la difusión de la primera metalurgia. Esta hipótesis de trabajo, absolutamente válida hace más de un cuarto de siglo, adolece a la luz de los conocimientos actuales de una excesiva simplicidad, pero fue recogida, de forma más o menos aproximada. por otros autores, e incluso alguno ha aplicado su terminologia a otras provincias del arte prehistórico.

Enlazando con el problema de las cronologias absolutas y relativas, seguramente vale la pena recordar las posiciones de varios especialistas que en 1960 -en el simposio del castillo de Wartenstein- expusieron sus puntos de vista refiejándolos en un cuadro que reproducimos en estas páginas (fig. 3).

A la vista del mismo, hay que recordar que para las fechas absolutas, el abate Breuil propugnó siempre una edad paleolitica. Los investigadores españoles demostraron que el arte llamado “levantino" se desarrolló entre el Epipaleolítico y el comienzo de la Edad del Bronce, cubriendo todo el Neolítico y el Eneolítico y recibiendo a partir de ellos ciertos influjos exteriores que se acentúan con la llegada de los primeros metaliferos y el paso de la pintura hacia lo esquemático. Debe ser citada, asimismo, la teoria tendente a colocar todo el desenvolvimiento de lo levantino dentro de la Edad de los Metales ( $F$. Jordá).

Gracias a los trabajos de diversos autores, pero en particular de E. Hernández-Pacheco y $\mathrm{M}$. Almagro Basch, se ha hecho irrefutable la fecha postpaleolitica. Por nuestra parte, seguimos pensando que, durante el largo periodo en que se fueron introduciendo y enraizando las innovaciones neolíticas en una sociedad de cazadores-recolectores, esta facies artística levantina se habria desarrollado en toda su complicación y esplendor, al parecer con un cierto movimiento del naturalismo en sentido de norte a sur. Las disparidades de aquel cuadro y de aquel momento se hacen evidentes, igualmente, en las diversas opiniones sobre la relación de lo levantino y lo esquemático. Debemos decir algo de este último 


\begin{tabular}{|c|c|c|c|c|c|}
\hline & BREUIL & PERICOT & ALMAGRO & RIPOLL & JORDA \\
\hline \multicolumn{6}{|l|}{ AURIGNACIAN } \\
\hline \multicolumn{6}{|l|}{ GRAVETIIAN } \\
\hline \multicolumn{6}{|l|}{ SOLUTRIAN } \\
\hline \multicolumn{6}{|l|}{$\begin{array}{l}\text { EPISAVE T. IA EAST SPA } \\
\text { MAGDALNIAN }\end{array}$} \\
\hline \multicolumn{6}{|l|}{ MESOLITHIC } \\
\hline \multicolumn{6}{|l|}{ NEOLITHIC } \\
\hline \multicolumn{6}{|l|}{ BRONZE AGE } \\
\hline IRON AGE & & $?$ & & 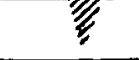 & \\
\hline
\end{tabular}

Fig. 3. Diversas hipótesis sobre la cronología de las facies levantina y esquemática del arte postpaleolítico de la Península lbérica: $H$. Breuil, L. Pericot, $M$. Almagro, E. Ripoll y F. Jordá (trazado por E. Ripoll en el simposio de Wartenstein, 1960).

En la periferia o superpuestos a los frescos naturalistas o seminaturalistas de ciertos lugares de la España oriental, se encuentran figuras de claro carácter esquemático o abstracto, evidentemente más modernas. Constituyen la manifestación de otra facies artística, ya de la plena Edad de los Metales, que se extiende, de forma abundante, por la casi totalidad de la Peninsula Ibérica, en abrigos abiertos y, a veces, casi a la intemperie. Los núcleos más densos se hallan en las provincias de Almería y Cádiz, en toda Sierra Morena, en Extremadura y algunas zonas de La Meseta, como Soria y Salamanca. Centenares de rocas pintadas contienen representaciones zoomorfas y antropomorfas convencionales que, en ocasiones, por su grado de abstracción, parecen signos de una escritura arcaica (algunos autores les reservan el nombre de "pictografías").

La temática esquemática está derivada, en parte, de la propia facies 
levantina y es posible que hubiera momentos en que estadios próximos de ambas facies fueran contemporáneas (queremos decir que, mientras un artista todavía pintaba en forma seminaturalista, otro pudo hacerlo en una forma más sintetizada, más esquemática). El resto de las figuras - simbolos solares y estelares, ídolos, simbolos del agua, etc.-, parece corresponder a la implantación de una nueva mentalidad religiosa, en parte, al menos, de procedencia oriental y que, en el aspecto funerario, estaría representada por los monumentos megalíticos en las regiones donde éstos existen.

El conocimiento científico de esta etapa tardía del arte rupestre postpaleolítico parte de Juan de Góngora y Martínez en el siglo XIX. Los estudios fundamentales se deben al abate Henri Breuil, Juan Cabré y Aguiló y E. Hernández-Pacheco en la primera mitad del siglo $x x$, siendo notables en nuestros días las aportaciones de Pilar Acosta, T. Ortego, J. A. Gómez Barrera, L. Diez-Coronel, A. Caballero Klink, J. Becares, J. Carrasco Rus, F. Costa Goberna, F. J. González-Tablas, R. Grande del Brio, M. López Payer, M. Soria Lerma, Rosario Lucas, M. Mas Cornellà, Julián Martínez Garcia y J. L. Sanchidrián, entre otros muchos.

Además de la dinámica evolutiva propia del arte postpaleolítico como conjunto, parece que esta facies esquemática se extendió desde el Sudeste de la Peninsula al resto de la misma y que sus frisos se encuentran con cierta frecuencia asociados a no lejanos lugares de habitación. Aunque con los indicados elementos nuevos con respecto a la facies levantina, la temática principal sigue siendo la cinegética (aunque hay un claro contraste en el consumo de animales salvajes y de animales domésticos - mucho mayor éste-, atestiguado por los yacimientos que cabe poner en relación con las pinturas). Ante sus figuras debian tener lugar ceremonias en relación con ritos funerarios, de propiciación de los agentes atmosféricos, de la fecundidad vegetal, animal y humana, venatorios, etcétera. Muchas de las imágenes debian tener, al mismo tiempo, un carácter votivo. Los conjuntos de El Tajo de las Figuras (Cádiz), la cueva de La Graja (Jaén) y la cueva —en realidad reducido abrigo- de Los Letreros (Vélez Blanco, Almeria), se cuentan entre los más típicos de esta etapa. En el último citado se encuentra la estupenda figura de un hombre con unos grandes cuernos de macho cabrio que empuña una hoz en una de sus manos y que podría, por su simbologia agrícola y cazadora al mismo tiempo, ser considerado como emblemático de esta facies artística que se encuentra ya cerca de las fronteras de la Protohistoria. En Extremadura existen interesantes abrigos pintados, algunos de los cuales contienen representaciones de carros, que son análogas a las 
que figuran en las denominadas "estelas del suroeste". En Asturias, la roca de Peña-Tu (Llanes), contiene un gran idolo, figuras humanas y puntuaciones, todo ello pintado junto a la representación de un puñal de bronce grabado. Hay otros lugares en la cornisa cantábrica, pero no alcanzan la densidad de los abrigos pintados o grabados de la España central, donde, sin duda, el futuro reserva todavía numerosos e importantes hallazgos.

Otra provincia de arte rupestre postpaleolítico, conexa, al menos en parte, con la fase esquemática, es la de los grabados, insculturas o petroglifos de Galicia y norte de Portugal, con manifestaciones relacionadas que se hallan más al sur como, por ejemplo, las del valle del Tajo. La perduración en algunos lugares hasta la avanzada Edad del Hierro es muy probable. Sobre las rocas de aquellas regiones se encuentran millares de figuras, algunas seminaturalistas y otras claramente esquemáticas y abstractas. Se trata de imágenes grabadas absolutamente al aire libre, en una forma que $F$. Jordá ha calificado acertadamente como "santuarios horizontales". En el valle del Tajo casi toda la iconografía se reduce a símbolos. En el área galaico-portuguesa hay zoomorfos y los signos se concretan particularmente en la espiral y el laberinto. Este último tema es sin duda el más característico, presentando una tipologia compleja. En Galicia, Campo Lameiro constituye uno de los conjuntos más completos. No conocemos la conexión entre el arte esquemático meseteño y los petroglifos, aunque nos parece que se podrá demostrar si se tiene en cuenta, como caso conocido, el de los grabados del castro salmantino de Yecla de Yeltes.

Los trabajos pioneros sobre este tema y esta área son los de $F$. López Cuevillas, R. Sobrino Buhigas y R. Sobrino Lorenzo-Ruza. Descuidada durante bastante tiempo, ahora se ocupa de la investigación de los petroglifos una pléyade de jóvenes investigadores con notables aportaciones como las de A. de la Peña, A. Garcia Alén, A. M. Baptista y J. M. Vázquez Varela, entre muchos otros.

Además, en relación con monumentos en general bien fechados, está el arte de los grabados - $y$ aigunas pocas pinturas- que presentan algunos sepulcros dolménicos. En ellos hay que distinguir los contemporáneos a su erección de los realizados después de su abandono o desmantelamiento. En el tema deben ser incluidos los menhires $y$, por extensión, las estatuas-menhires. En toda esta cuestión trabajaba el malogrado Fernando Piñón Varela, cuyos sistemáticos estudios merecerian ser continuados. 


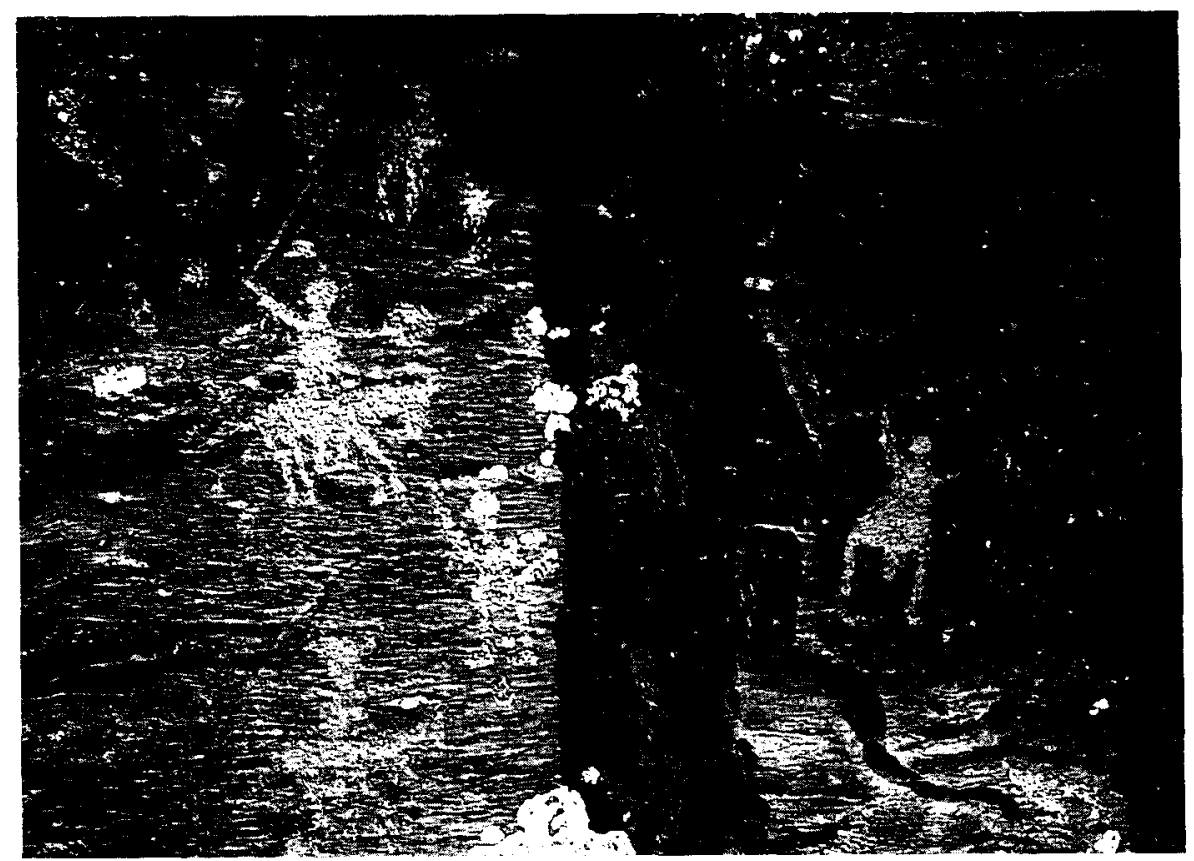

Fig. 4. Grabados representando jnetes, seguramente tardorromanos o altomedievales, Domingo Garcia (Segovia). (Foto E. Ripoll).

A nuestro parecer, después de las fases esquematico-abstractas de la Edad del Bronce, el arte postpaleolitico de la Península Ibérica tuvo una larga perduración en el tiempo en lo que podriamos llamar "zonas residuales", con el momentaneo resurgir de formas anteriores, y que pudo enlazar con ciertas manifestaciones, votivas o no votivas, altomedievales - por ejemplo, una buena parte de los grabados de Domingo Garcia (Segovia) (fig. 4), pasando por las épocas ibérica - grabados de Pozondón (Teruel) - y romana - grafitos de Cogul-.

Con la suma de las manifestaciones levantinas, esquemáticas, galaico-portuguesas, etc., nos hallamos pues ante una compleja etapa del arte rupestre prehistórico, bien situada en un espacio geográfico -la 
Peninsula Ibérica - y relativamente bien encuadrada en un marco cronologico. con raices en el Epipaleolítico y con una duracion hasta la tardia Edad del Bronce. teniendo incluso perduraciones. Como tantas otras provincias de arte rupestre en todo el mundo, el arte parietal postpaleolitico de la Peninsula Iberica plantea numerosos problemas. Algunos de ellos podran ser resueltos con la ayuda de nuevos hallazgos arqueológicos o con el aumento del numero de sitios conocidos con obras de arte: otros trabajos permitirán aproximaciones a lo que desde nuestra optica nos parezcan soluciones o hipotesis verosimiles. mientras que otras incógnitas. abundantes. por último. seguirán siendo insolubles. Personalmente, siempre teniendo en cuenta los avances de la investigación. inspirándonos en el cuadro del simposio de Wartenstein. que ya hemos reproducido y comentado. creemos poder reflejar las opiniones que en este momento sustentamos en el sintético cuadro adjunto (fig. 5).

La complejidad de esta problemática es grande y en este breve texto debemos limitarnos a evocar algunos de sus aspectos. en el bien entendido de que muchas otras cuestiones están únicamente planteadas, o incluso, en las limitaciones de nuestro conocimiento, ni siquiera se han abierto a la perplejidad de los numerosos investigadores que trabajan sobre esta importante etapa artística.

Uno de los primeros problemas que se presentan, importante pues afecta a la "lectura" misma de las obras de arte, es el de la nomenclatura, tema del que ya nos hemos ocupado en alguna ocasión. Para palabras tales como: a) "realismo" (o naturalismo, aunque no siempre se utilizan de forma sinónima), b) "estilización", c) "esquematismo" y d) "abstracción», habria que ponerse de acuerdo sobre qué quisieron decir los investigadores que nos han precedido y a qué se refieren los que en la actualidad los utilizan. Nos parece que seria conveniente llegar a un consenso para su uso de cara a las futuras investigaciones. Mi propuesta, que, por lo que sé, no ha encontrado ningún eco explícito, era la siguiente. La denominación a) equivaldría a la "representación que imita fielmente a la naturaleza, con detalles abundantes que permiten una determinación precisa de lo figurado". Para b) se podría entender la "representación convencional que hace resaltar los rasgos más característicos". La definición para c) sería "la representación convencional que subraya unos rasgos minimos para la identificación de una figura". En último lugar cabria definir d) como "la representación en la que, por un proceso mental, se ha excluido todo detalle explicativo para señalar una cualidad o significado que pueden ser sólo comprendidos mediante un conocimiento o convención previos". Asimismo, el "proceso de esquematización" sería posible explicarlo como "la reducción progresiva de los detalles de las 
Epipaleolitico
Neolitico cardial

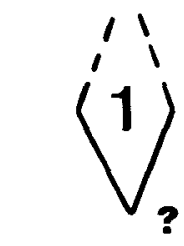

Neolitico medio

Neolitico final

Eneolitico

Edad del Hierro

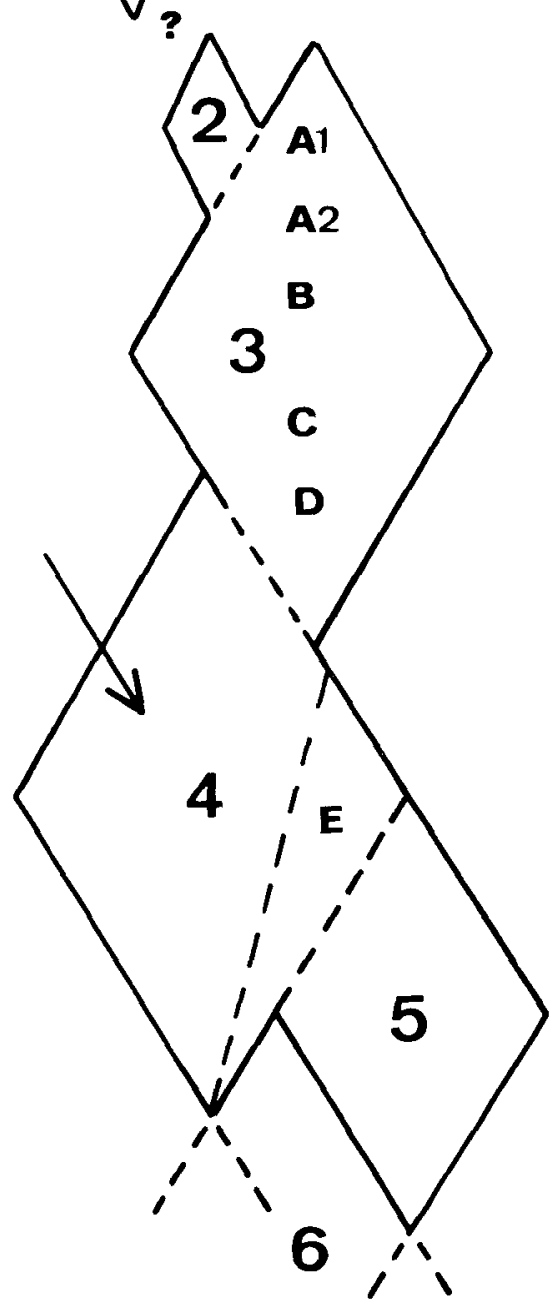

Fig. 5. Hipótesis sobre la secuencia cronologico-cultural de las diferentes facies del arte postpaleolitico de la Península lbérica: 1, lineal-geométrica; 2, macroesquemática: 3, levantina (con la seriación de E. Ripoll); 4, esquemática (la flecha indica las influencias extrapeninsulares; la letra $E$, los grabados de esta fase); 5 . petroglifos, y 6. perduraciones. (Según E. Ripoll, 1989). 
representaciones hasta conseguir que queden un número minimo de rasgos que permitan la identificación al menos de una manera aproximada". El esfuerzo en definir y perfeccionar esta nomenclatura y fijarla respecto a una cronologia relativa permitira perfeccionar el conocimiento del proceso evolutivo.

Aproximaciones al "proceso de esquematizacion" las hemos planteado en otros lugares (con concreto análisis de los frisos de Cogul. Alpera y Minateda). aduciendo los paralelos arqueologicos. reforzando la secuencia cronológica relativa de lo levantino e incluso haciendo un intento de seriacion morfológica de las figuras antropomorfas dentro de la facies levantina y esquematica (fig. 6). Pero es preciso avanzar mas. y resolver. por ejemplo. Ia seriacion de las figuras zoomorfas en dicho periodo. o el de la sistematizacion morfológica de las figuras de la transicion de lo levantino a lo esquemático. la formacion de un repertorio iconografico de temas "importados". o tambien a la clasificacion y. en algunos casos. posible identificación. de las representaciones abstractas que acaso seria mejor llamar «ideogramas».

Conviene ahora decir algo de los comienzos del arte postpaleolítico en el Levante. Para el abate Breuil. desde los anos veinte. la primera fase de Minateda. anterior a las representaciones de tipo levantino. era bastante esquematica. aunque figurativa y de pequeño tamaño. de color rojo claro y con un neto predominio de las figuras humanas con respecto a las de animales (60 y 20 ). yendo los hombres provistos de arcos simples y con frecuencia agrupados, representando uno de tales grupos el fragmento de una escena de guerra o de caza. Pero su aseveracion fue poco atendida e incluso discutida. principalmente por E. Hernandez-Pacheco. que partia de los calcos del mismo lugar efectuados bajo su dirección por F. Benitez Mellado. El autor que suscribe no vio dicha fase en su examen y seriación del friso de Minateda (recuérdese el lamentable estado de conservación en que se encuentra). rechazo - y sigue haciendolo- dicha atribución y en 1966 escribio: "En estas cuestiones de influjos externos y de evolución interna. creemos que se equivocaba el abate Breuil al atribuir a una población "conchilofaga" local de pintores esquematicos - ¿cual y dónde estarian las otras manifestaciones. artisticas o materiales, de su existencia? - la por él considerada primera fase de Minateda. que habria sido sumergida por una oleada de cazadores paleolíticos llegados del Norte" ("Cuestiones en torno a la cronologia del arte rupestre postpaleolitico...». nota 4 y pags. 179-180). Con referencia a una hipótesis de $F$. Jorda acerca de una relación entre la dispersión de las pinturas levantinas y el mapa de la cultura megalitica. que serian áreas "complementarias". expusimos nuestro parecer de que precisamente ahi 

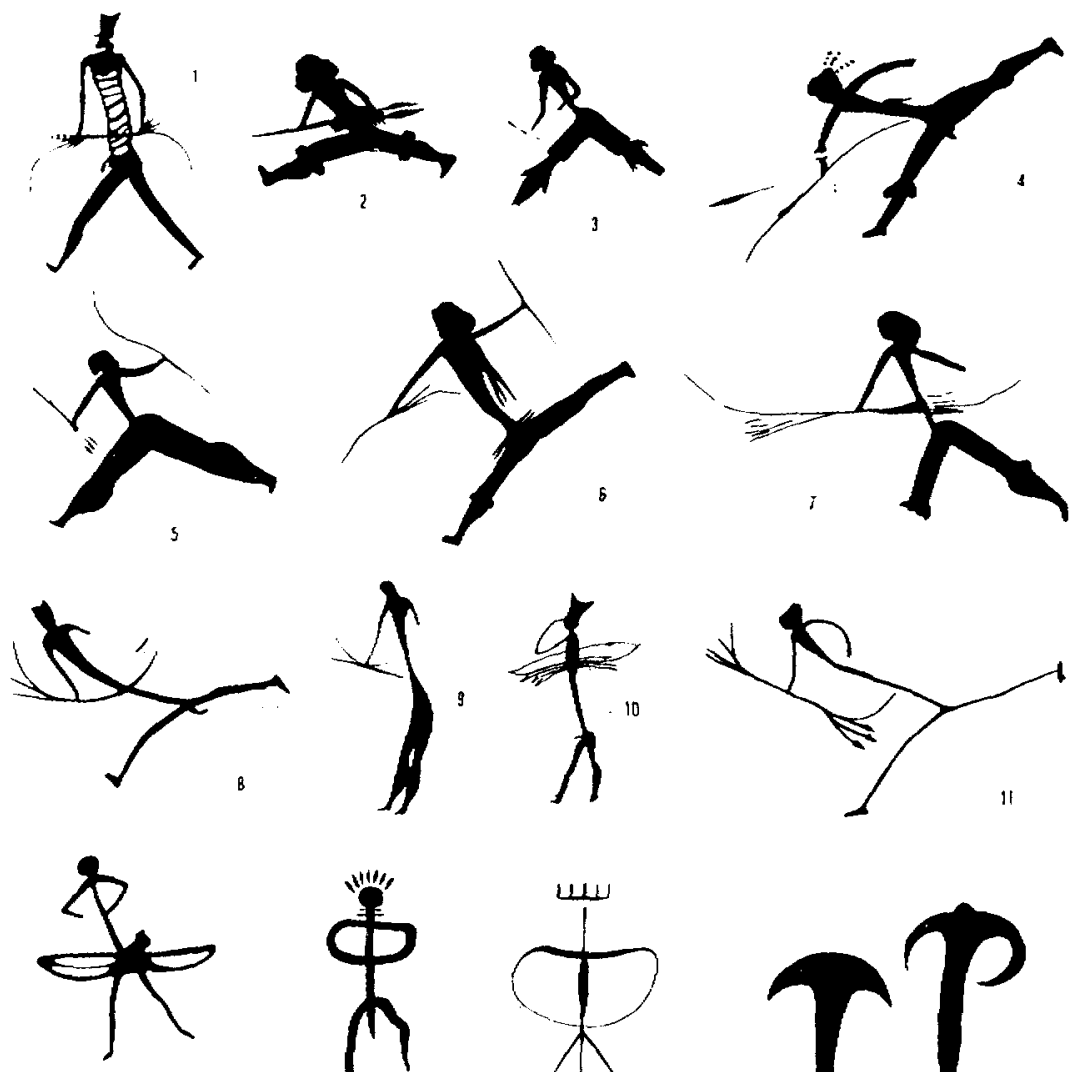

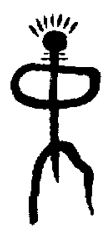

13

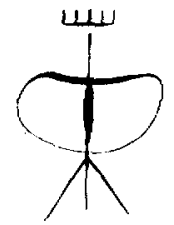

11

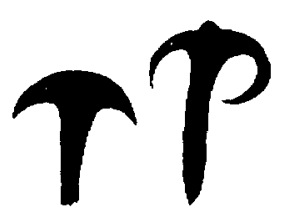

15

Fig. 6. Esbozo de una seriación de las representaciones antropomorfas del arte postpaleolitico de la Peninsula Ibérica. (Según E. Ripoll. 1977). 
se demuestra la independencia de aquéllas respecto al mundo dolménico. Lo que si demuestra dicho gráfico es la estrecha relación de la cultura megalítica con la facies esquemática. Dimos en 1966 el mapa correspondiente (fig. 7) y creemos que por vez primera planteamos la posible relación del arte levantino con las cerámicas cardiales, trazando también un mapa según los conocimientos del momento. Por entonces, F. Jordá había dicho: "casi todos los especialistas se inclinan a aceptar puntos de contacto entre estas pinturas y las gentes neolíticas. La única diferencia que presupone mi hipótesis es que mientras ellos consideran el mundo neolítico como el capítulo final del arte levantino, yo considero que es el principio" (Jordá, "Notas para una revisión de la cronología...", págs. 56-58). Por nuestra parte replicamos lo siguiente: "Para nosotros el momento álgido y gran parte del período clásico del arte levantino coinciden con el Neolítico inicial, como bien puede verse en el cuadro, que el mismo Jorda reproduce, de Prehistoric Art of the Western Mediterranean and the Sahara, pág. XI... Por otra parte, Jordá, que valora debidamente el Neolítico inicial con cerámica cardial, no compara la difusión de ésta con la del arte levantino. Aun teniendo en cuenta que bajo la etiqueta de cerámica cardial se han incluido materiales epigónicos que pueden ser muy posteriores (¿los del Bajo Tajo?), si trazamos un mapa de aquellos dos fenómenos culturales vemos que su coincidencia es bastante aproximada. En algún caso la vecindad de los hallazgos es muy significativa, así, por ejemplo, en el Bajo Aragón, el fragmento cardial de la Apotecaría dels Moros de Mazaleón, relacionable con los abrigos pintados de Caidas del Salbime y de Els Secans. Probablemente cuando se conozcan mejor los contextos arqueológicos de la cerámica cardial, en especial los líticos, se podrá avanzar más por este camino" (Ripoll, "Cuestiones en torno a la cronologia del arte rupestre postpaleolítico...", pág. 181).

Más recientemente, en los años setenta, Antonio Beltrán señaló tres casos en que signos esquemáticos geométricos están infrapuestos a figuras levantinas: La Sarga, La Araña y Cantos de la Visera. Respecto al primero de estos lugares (fig. 8), dicho autor escribió: "hay numerosos trazos y signos esquemáticos, en color rojo claro, que han de corresponder a la fase más antigua de todo el conjunto de pinturas; sobre ellos se han pintado ciervos naturalistas, de dos estilos, sin que exista la menor duda sobre este hecho, estableciéndose asi una cronología relativa evidente... Los signos han de ser forzosamente anteriores, y a juzgar por la conservación, muy anteriores, cabrian en la fase I, del 6000 al 3500, con apogeo antes del 5000». Esto lo ponía en relación con «... el arte mobiliar totalmente geométrico o abstracto, hallado en el nivel mesolítico de la 


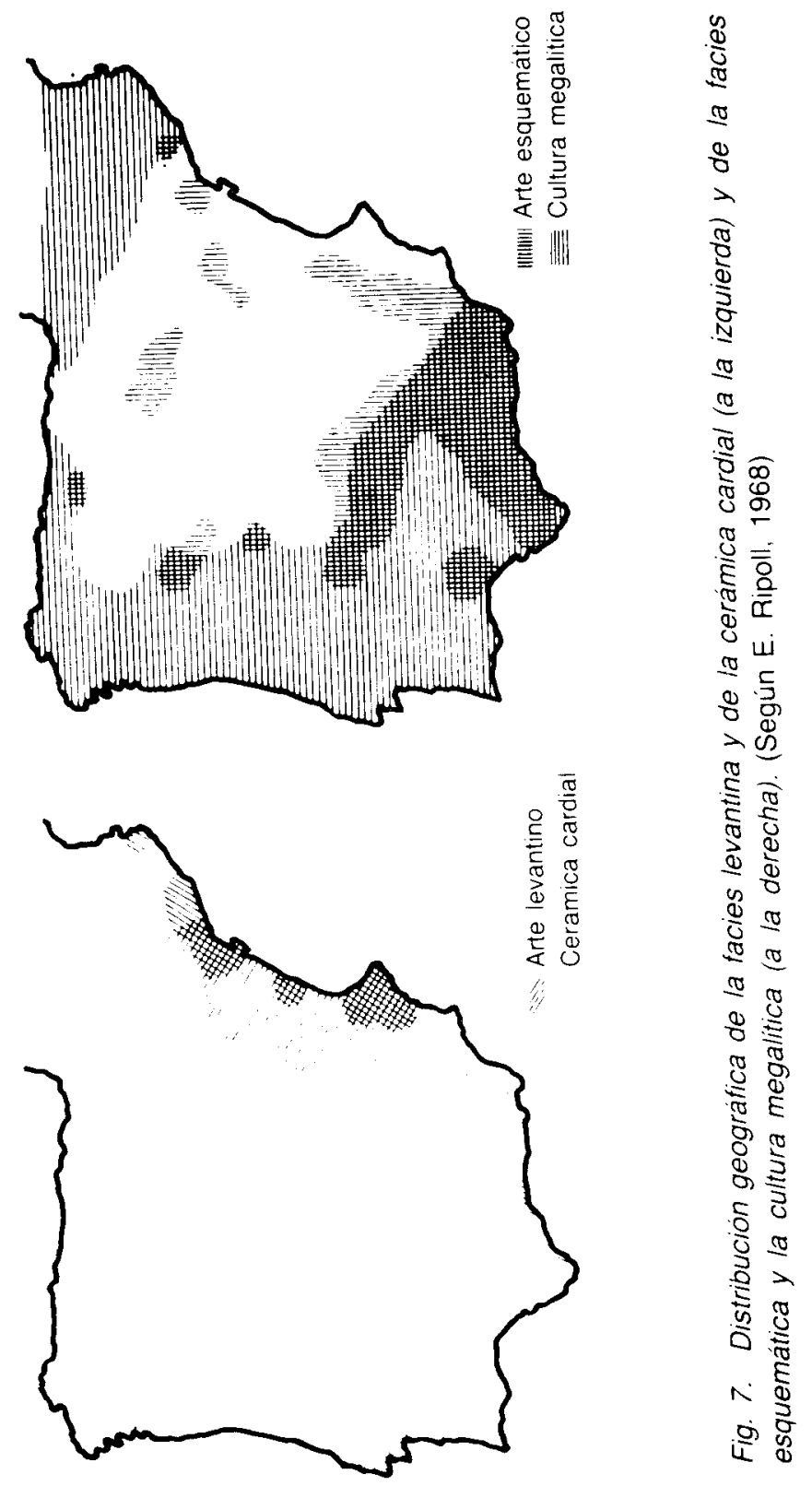


cueva de La Cocina..." (Beltrán. Las pinturas rupestres prehistoricas de la Sarga.... págs. 47-48: y Arte rupestre levantino. pág. 67).

Casi al mismo tiempo. despues de la publicación del sitio de La Sarga. F. J. Fortea aporto algunos notables trabajos a esta problemática. Al hablar de las pinturas parietales descubiertas por L. Pericot y de la cronologia epipaleolítica de las plaquetas de la cueva de La Cocina (Dos Aguas) - de los estratos inmediatamente anteriores a la primera aparición de la ceramica cardial. lo que debe ser tenido en cuenta por lo que se dirá más adelante-. establecia su relación con las mencionadas figuras de La Sarga. La Araña y Cantos de la Visera. Para el. configuraban un "concepto artistico lineal-geométrico... Por todo ello no nos pareceria imprudente poner la fecha del 5000 como gozne entre los dos conceptos artisticos. sin perjuicio de que el mas antiguo pudiera seguir perdurando. y sin tener en cuenta la tardanza logica con que llegaria el cardial a La Cocina, yacimiento muy interior por sus dificultades orográficas. Io que nos llevaria a acortar aquella fecha" (Fortea. "En torno a la cronologia...". pág. 189).

Cuando. en 1982. en el Coloquio de Arte Esquemático de Salamanca, Mauro S. Hernández Perez y sus colaboradores del Centre d'Estudis Contestans presentaron los calcos de algunos de sus sorprendentes descubrimientos en la zona norte de la provincia de Alicante. todo el problema de los origenes del arte postpaleolítico peninsular vino a hacerse más complicado. Despues de varias publicaciones de avance. en 1988 se publicó un nutrido libro que presenta dichos hallazgos. En menos de diez años se aportaba al arte prehistorico español un conjunto iconográfico localizado en más de cien abrigos de desigual importancia, pero algunos con la singular novedad de presentar una nueva facies artistica. hasta el momento sólo conocida en La Sarga que era considerada hasta entonces como un unicum. Los descubridores le dieron el nombre de "arte macroesquemático" '. Se caracteriza "por sus grandes figuras humanas y los serpentiformes-meandriformes verticales y. excepcionalmente. horizontales. Entre los antropomorfos, agrupados en cuatro tipos. destacan aquellos representados en actitud de orante" (Arte rupestre en Alicante, pág. 257) (fig. 9). Al mismo tiempo. Bernat Marti Oliver. en los fondos del Servicio de Investigación Prehistorica de Valencia. y en sus

Se han propuesto otros nombres: Arte lineal-figurativo (Aura Tortosa). Arte contestano (Jorda). Arte cardial (Fortea) y Fase prelevantina (Beltran). Aunque tenga poco de esquemático en el sentido en que nosotros entendemos este calificativo y que lo que en el predomina es lo simbolico, a nuestro parecer hay que respetar el derecho de prelacion de los descubridores al darle dicho nombre que. ademas. nos parece poco eufonico. 


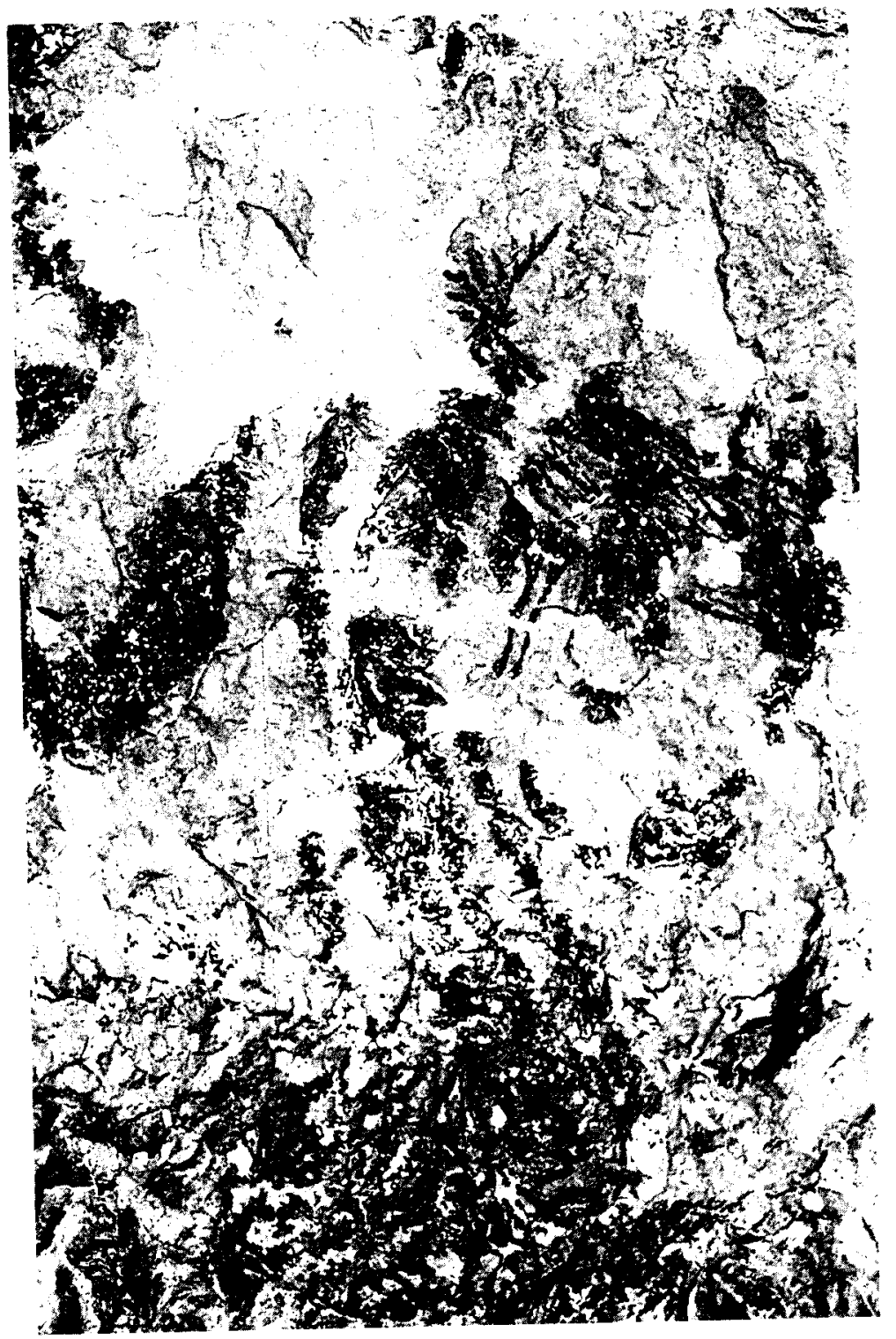

Fig. 8. Fragmento del friso pintado de La Sarga (Alcoy. Alicante). con ciervos superpuestos a grandes signos ondulados. (Foto E. Ripoll). 


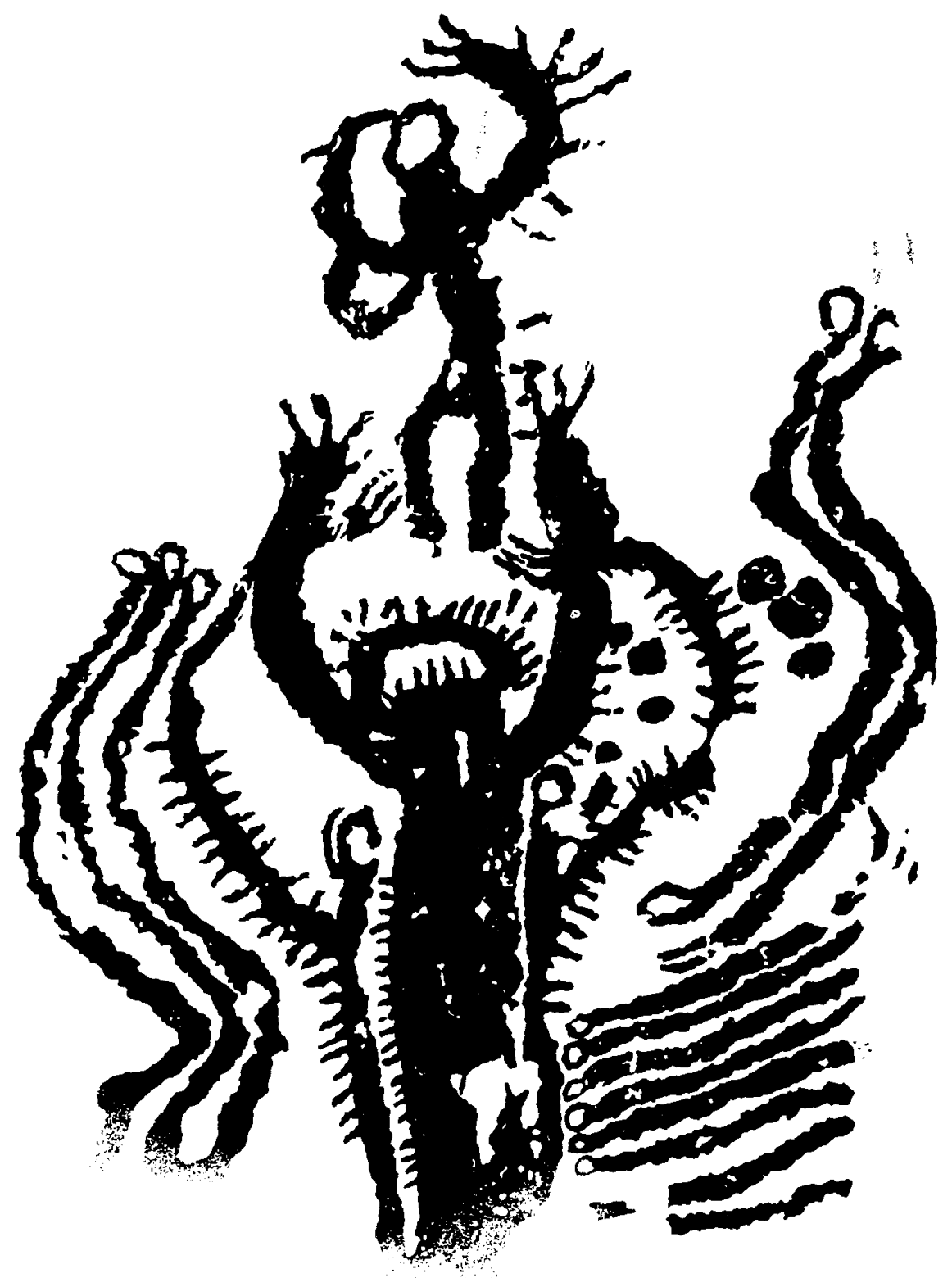

Fig. 9. Idolo del abrigo $V$ del Plá de Petracos (Castell de Castells, Alicante) Altura, 1.80 metros. (Según M. S. Hernández y C.E.C.). 
propias excavaciones. encontraba diversas representaciones figuradas sobre cerámicas cardiales e impresas de la Cova de l'Or (Beniarres). En ellas. algunas de las figuras zoomorfas podian relacionarse con el arte levantino. pero las antropomorfas eran exactos paralelos de las figuras en el arte macroesquemático.

Los ejemplos de este último se hallan de forma clara e indudable en una decena de lugares: La Sarga (Alcoia). Coves Roges de Benimassot (El Comtat). Coves Roges de Tollos (El Comtat). Santa Maira del Barranc de Famorca V y VI (Marina Alta). Raco de Sorellets (Marina Alta). Pla de Petracos IV. VI. VII y VIII (Castell de Castells. Marina Alta). Barranc de Beniali IV (La Vall de Gallinera. Marina Alta) y Barranc de I'Infern II (La Vall de Laguart. Marina Alta). Para la superposición de lo levantino sobre lo macroesquematico el lugar con más evidencias sigue siendo La Sarga. aunque tambien se ha aducido Barranc de Beniali IV. Tan importante como esto nos parece la identificación de los "idolos" macroesquematicos con imagenes representadas en ceramicas cardiales (fig. 10) y otras figuras sobre ceramicas impresas pero no cardiales que corresponderian a lo levantino. todas ellas de la Cova de l'Or (Beniarres). tema al que ya hemos aludido. Para Mauro S. Hernandez: "Podría conectarse. aunque reconocemos la ausencia de argumentos definitivos que lo confirmen. con las poblaciones epipaleoliticas locales. ios autores del Arte lineal-geometrico. que ante el impacto de los neoliticos del Arte macroesquematico. convierten su manifestación artistica en rupestre. de ahi la perduración de algunos motivos de un arte que hasta este momento era exclusivamente mueble. y mediante escenas. con o sin sentido simbolico. narran un proceso de cambio cultural. como propone F. J. Fortea. cuya difusion por la fachada oriental de la Peninsula Ibérica es paralela a la de la neolitizacion" (Arte rupestre en Alicante. pags. 257-258). O sea que. en un lapso de tiempo bastante corto y en el reducido ambito geografico de la Contestania. se habria producido el paso de lo lineal-geométrico a lo macro esquematico y que este habria generado in situ el arte naturalista del Levante que. desde ese mismo espacio. se habria extendido al resto de la España mediterránea. Como veremos más adelante. lo mismo se propugna para la fase esquemática. Todo ello si entendemos bien la teoria y la interpretación de los hechos de Mauro S. Hernández y Bernat Marti.

Otra notable aportacion al tema ha sido la publicación excelente de los materiales ceramicos (bellos dibujos y fotografias) a que se ha hecho alusion, como complemento de una exposicion de los mismos organizada por el SIP (EI Neolitic valencià. Art rupestre i Cultura material. de Bernat Marti Oliver y Mauro S. Hernández Pérez. 1988). Como en ia publicación 
de conjunto antes citada, se insiste en ésta en la denominacion y en las caracteristicas generales del arte "macroesquemático" y su estrecha relación con las cerámicas cardiales valencianas. llegandose a la identificación de varios tipos de antropomorfos. que para nosotros presentan la nota comun de ser "oferentes". En este sentido los autores escriben: " Es obligado preguntarse si a los distintos antropomorfos correspondería una diversidad de significados, y la respuesta más probable parece positiva. máxime cuando la unidad de técnicas decorativas que muestran éstas y otras representaciones que luego veremos sugiere un tiempo muy corto para plantear la hipótesis de la evolución tipologica como causa principal del variado panorama que se nos ofrece" (pag. 26). La pertenencia a la cultura de las cerámicas impresas mediterraneas y sus connotaciones en el Egeo, Chipre. Levante sirio-palestino y Anatolia. parece fuera de duda. Pero nos gustaria preguntar si se han buscado posibles paralelos en las cerámicas cardiales peninsulares de fuera de la region valenciana. Ademas, procedentes de las últimas campañas de excavaciones en la Cova de l'Or. presentan dichos autores dos fragmentos de ceramica impresa, uno con la cabeza y parte del cuerpo de un cáprido y otro con la parte posterior de lo que parece ser un bovido junto con la parte posterior de la cabeza y cornamenta de un ciervo (fig. 11). Para este caso. B. Marti y M. S. Hernandez. más alla de su grado de "naturalismo» o "esquematismo". encuentran los paralelos en el arte levantino. situando los fragmentos en «momentos avanzados del Neolitico antiguo. todavia en contextos cardiales" y los colocan cronologicamente en los siglos finales del $\mathrm{V}$ milenio. Insisten, al propio tiempo. en la antigüedad de las formas de arte esquemático, 10 que les hace proponer. con F. Jorda, que el origen de todas las facies del arte postpaleolítico está en lo macroesquemático. Pero lo cierto es que las figuras incompletas de aquellos fragmentos de cerámica impresa son de contorno lineal, sin que se hubiera recurrido al relleno de la figura, tipico - tinta planade lo levantino, tecnica que no les era desconocida como queda evidente en las representaciones del arte macroesquemático sobre ceramica cardial.

Antes de conocer estos descubrimientos, en el Coloquio Internacional de Arte Rupestre Esquemático de 1982, escribiamos: "En esta seriación comparativa quisiera destacar el hecho de que el abate Breuil hacia debutar el arte de Minateda con figuras bastante esquemáticas (su serie primera). Hecho que a mi parecer no es cierto, pero que, sin embargo. me parece que hay que tener en cuenta en futuras investigaciones". Aludia asi a las figuras de La Sarga. Cantos de la Visera y La Araña. de carácter no figurativo y calificadas como "geométricas", señaladas por $F$. $\mathrm{J}$. Fortea y A. Beltrán. Como hemos dicho, en aquella misma reunión de 


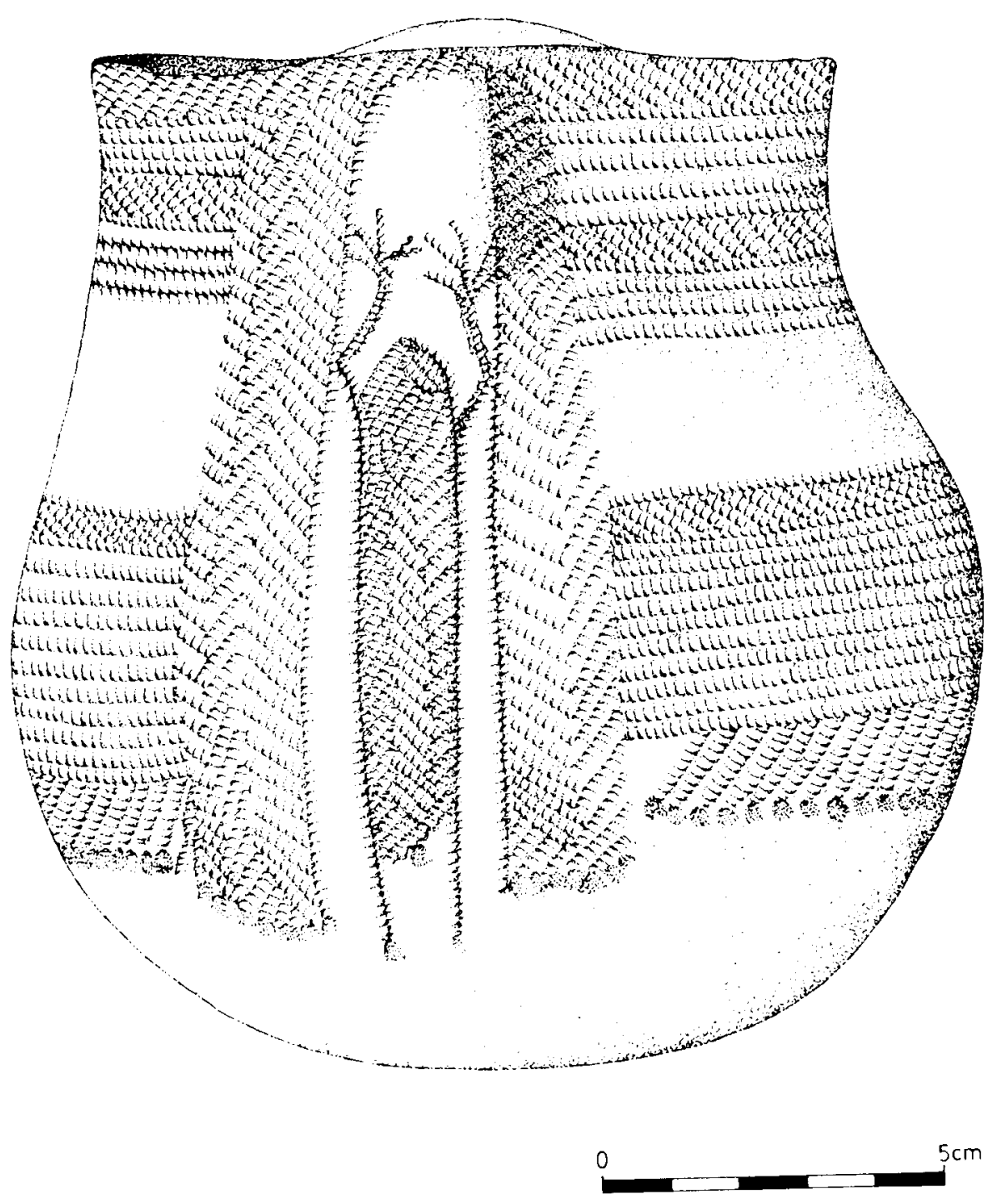

Fig. 10. Jarro globular de la Cova de l'Or (Beniarrés), con decoración cardial que encuadra una figura de orante. Altura, 15 centímetros. Museo Arqueológico de Alcoy. (Según B. Marti y M. S. Hernández). 
Salamanca se presentaron calcos de los importantes descubrimientos de la region de Concentaina y se pudo escuchar una comunicacion sobre los mismos luego publicada en las Actas. Mas tarde. el autor de la presente nota ha podido conocer de visu algunas de estas representaciones en su marco natural?

¿Como entender estos sorprendentes descubrimientos? Aunque. como queda dicho. ya contamos con una importante bibliografia sobre los mismos, pensamos que aun nos falta perspectiva para enjuiciarlos. ¿Se trata, para el arte "macroesquemático". de lo mismo que hay en Cantos de La Visera o en La Araña? Por el momento nos inclinamos a pensar que. en el caso de las nuevas representaciones del norte de Alicante. se trata de una fase iconográfica regional. alli anterior. aunque no muy lejana. a lo tradicionalmente considerado "levantino". presente en algunos abrigos de la misma región. Pero no podemos conocer el lapso de tiempo que pueda separar una de otra fase; personalmente pensamos que si existió debió ser muy corto. En el arte postpaleolitico peninsular hay otros hechos "regionales" que deben ser tenidos en cuenta y que indican a veces conservadurismo y otras constituyen una "vuelta hacia atrás" por una mayor inclinación de un artista determinado -o grupo de artistasal naturalismo o al seminaturalismo en un territorio determinado. Esto explicaria casos como los de ciertas figuras de Aldeaquemada (Jaen). claramente de estilo levantino. o el de Las Batuecas (Salamanca). seminaturalista y no lejano de aquél. o el de la persistencia en el seminaturalismo de las representaciones postpaleolíticas de los varios abrigos de la alta cuenca del rio Vero (opinión de Vicente Baldellou que. con razón. sostiene la continuidad absoluta entre lo naturalista y lo esquematico en dicha zona). Con este razonamiento volvemos al planteamiento inicial de las definiciones y a la evidencia de las transiciones sin demasiadas cesuras. Véase. por ejemplo, bien a occidente de la Peninsula. el caso de A Fraga d'Aia (Paredes de Beira. Portugal). con una escena de caza seminaturalista y una serie de antropomorfos semiesquemáticos. dandose la circunstancia de que. al pie de las figuras. se han encontrado materiales fechables entre la segunda mitad del III milenio y la primera mitad del II. A este proceso. todavia por estudiar a fondo. podriamos denominarlo "comarcalización».

En relación con todo lo anterior, y para ir avanzando, una cuestión que deberia suscitar el interés de los estudiosos es la concordancia entre

Respecto a las pinturas de La Sarga. siempre nos sentimos perplejos ante sus superposiciones. El lugar lo visitamos hace muchos años con el recordado don Vicente Pascual y a el hemos vuelto en varias ocasiones. 


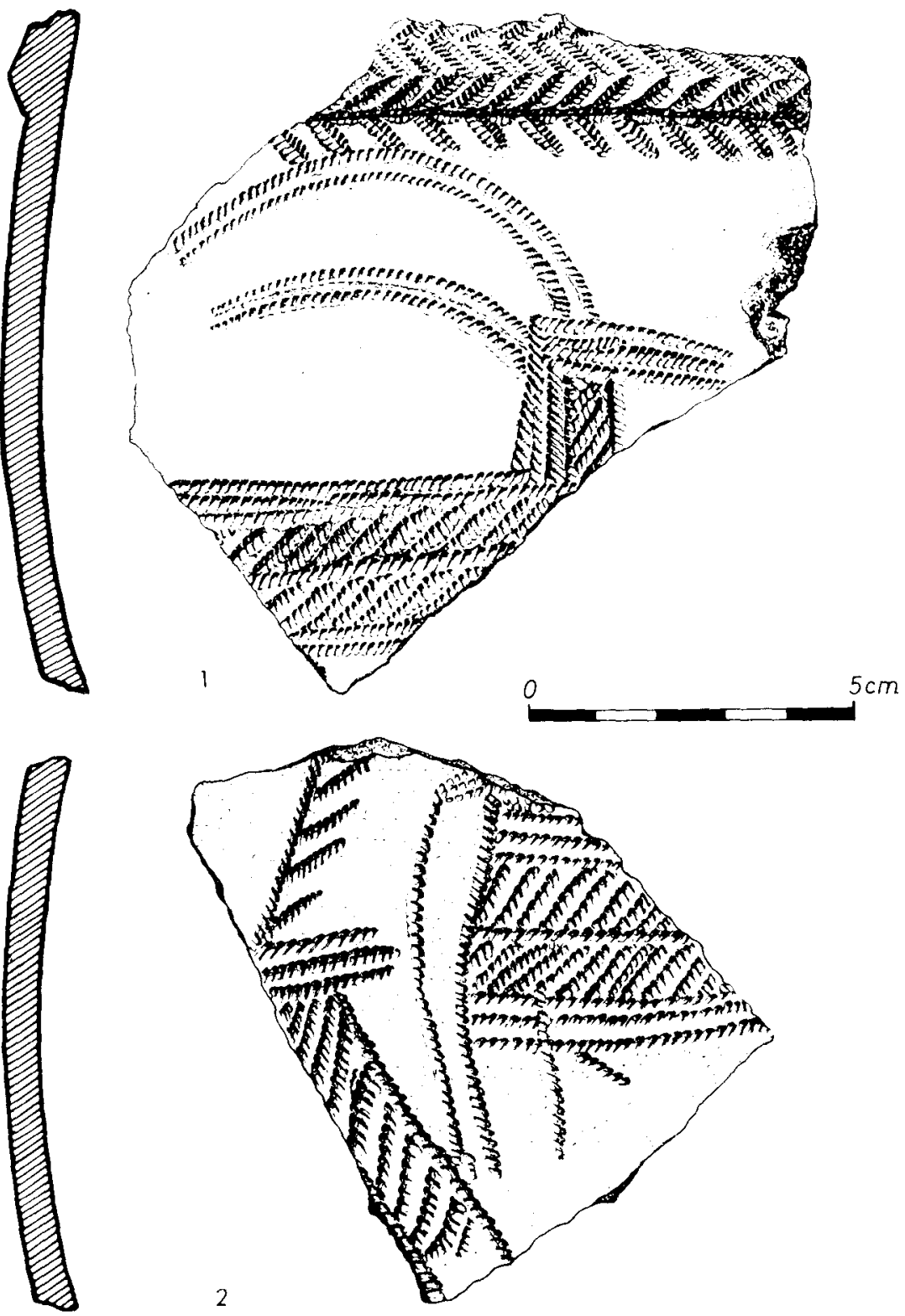

Fig. 11. Fragmentos de un vaso con decoración impresa de la Cova l'Or (Beniarrés). Arriba: cabeza, cuernos y parte del cuerpo de un cáprido. Abajo: parte trasera de un animal (¿bovidc?) y cornamenta y cuello de un ciervo. Altura, 10 y 8 centimetros, respectivamente. Museo de Prehistoria de Valencia. (Según B. Marti y M. S. Hernández). 
arte rupestre y documentos arqueologicos procedentes de yacimientos de las mismas áreas, o sea los correspondientes a concretas fases culturales. como hizo en su tiempo el abate Breuil. Ya hemos recordado que algo de ello intentamos en 1966. por ejemplo. el mapa de distribución del arte levantino superpuesto al de la difusion de las ceramicas cardiales. primer intento que sepamos de poner en relacion ambos fenomenos. Pero habria que profundizar mucho mas y hacerlo con territorios mas reducidos como han hecho. con acierto. los colegas valencianos B. Marti y M. S. Hernandez al establecer la relacion local entre decoraciones cardiales e impresas con el arte macroesquemático y levantino. Esa identidad ha sido objeto de agudo analisis critico, que suscribimos, por parte de Vicente Baldellou: concepciones artisticas distintas en las decoraciones alfareras y las representaciones rupestres: distinta finalidad de las mismas. utilitarias unas y probablemente rituales las otras: diferencias entre la difusión de las alfarerias cardiales. muy amplia. y la del arte macroesquemático. circunscrito a algunas comarcas alicantinas; relación limitada a las figuras de los orantes y falta de cualquier otra. etc. También los temas de la antigüedad de las facies levantina y esquematica y sus relaciones con las cerámicas impresas han sido objeto de amplio comentario de Baldellou que aduce las superposiciones que el estudia en la zona del rio Vero. aun teniendo en cuenta lo reducido de dicho territorio. Este es un indicio más de la complejidad de los problemas sin resolver. Como muy acertadamento dice $V$. Baldellou cel camino andado es mucho más corto que el que aún nos queda por recorrer y esto contando con que no nos hayamos equivocado de ruta" ("Algunas reflexiones...").

Ya en el estado actual del conocimiento. que no es poco. y a medida que se vayan conociendo nuevos lugares y en el analisis de los ya conocidos. será necesario proceder a comparaciones con el arte rupestre postpaleolítico del resto de Europa. pero principalmente con el del mundo mediterráneo y del mas inmediato Proximo Oriente. Admitido el hecho - por ejemplo. los "ojos de la diosa" - de la llegada de influjos de Oriente a Occidente. ¿habra que aceptar. asimismo. una via de retorno? Esto es lo que hacen pensar ciertos pequeños conjuntos. como el del Olmetta du Cap en la isla de Corcega. Otros. como la cueva de Porto Badisco. tan bellamente estudiada por el recordado Paolo Graziosi. retrotraen con seguridad a momentos mucho mas antiguos y corresponderian al itinerario en el primer sentido. Todos ellos presuponen frecuentes contactos por navegación. en expediciones que mas tarde repetiran y haran más sistematicas los pueblos colonizadores historicos. Unas cuantas representaciones de embarcaciones, pero principalmente el grupo que se 


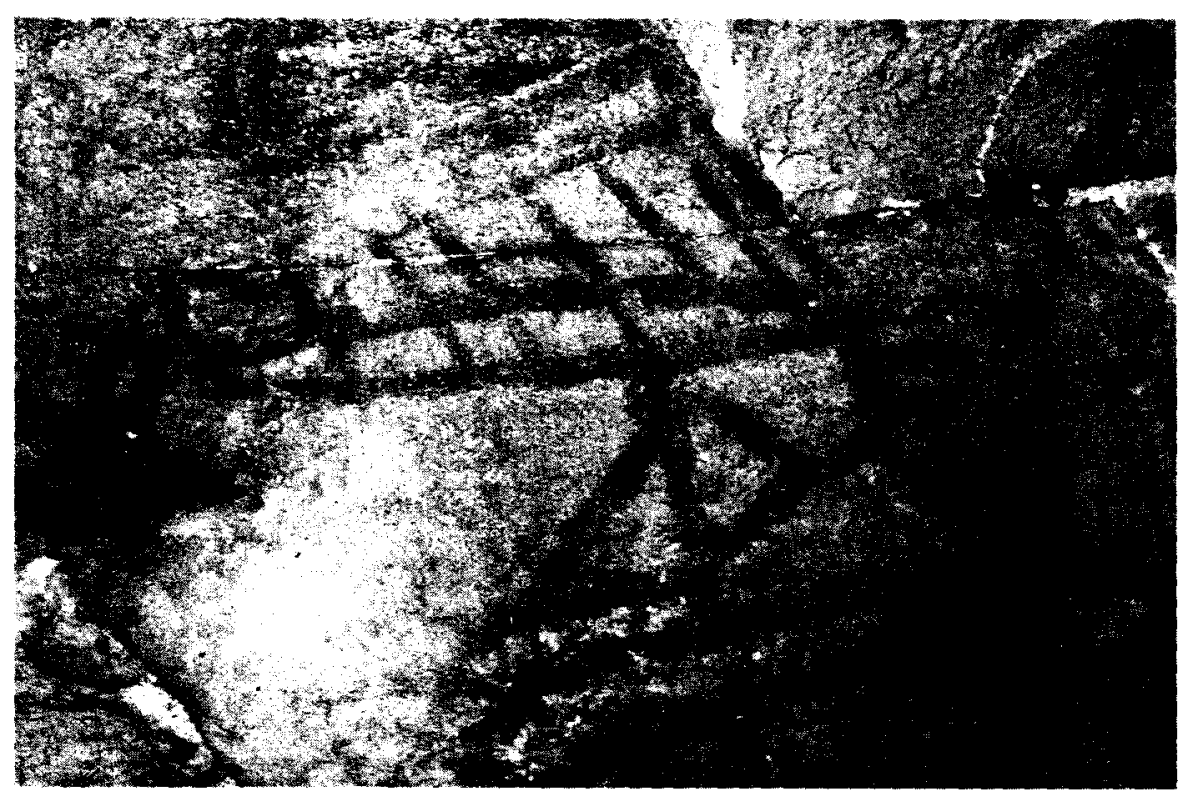

Fig. 12. Una de las embarcaciones (y parte de otra) de La Laja Alta (Jimena de la Frontera, Cádiz). (Foto Sergio Ripoll López).

halla en La Laja Alta (Jimena de la Frontera, Cádiz), vienen a apoyar to dicho.

Detengámonos por un momento en estos barcos de La Laja Alta (fig. 12). La colonización primera de las islas mediterráneas demuestra la muy alta antigüedad de las navegaciones en este mar que son patentes ya en el VI y $V$ milenios. Hacia el final del II milenio se puede rastrear ya una expansión que cabe llamar más propiamente colonial. Las cerámicas micénicas se encuentran en Sicilia, la italia central, Cerdeña e incluso Andalucia (según los hallazgos dados a conocer por J. C. Martín de la Cruz). En Occidente hay, despues, un hiatus hasta las navegaciones fenicias en la zona del Estrecho, abriendo el bien calificado "periodo orientalizante", en contactos que se convertirán en una oleada. Al mismo corresponderían los carros, escudos y otros elementos de las estelas del suroeste peninsular, ampliamente estudiadas por $M$. Almagro Basch. ¿Son de ese mismo momento, o son más antiguas, las embarcaciones de La Laja Alta? M. Almagro Gorbea se ha ocupado recientemente de las representaciones de barcos en el arte rupestre de la Peninsula lbérica, con particular atención a los de La Laja Alta, «8 navios de variado 


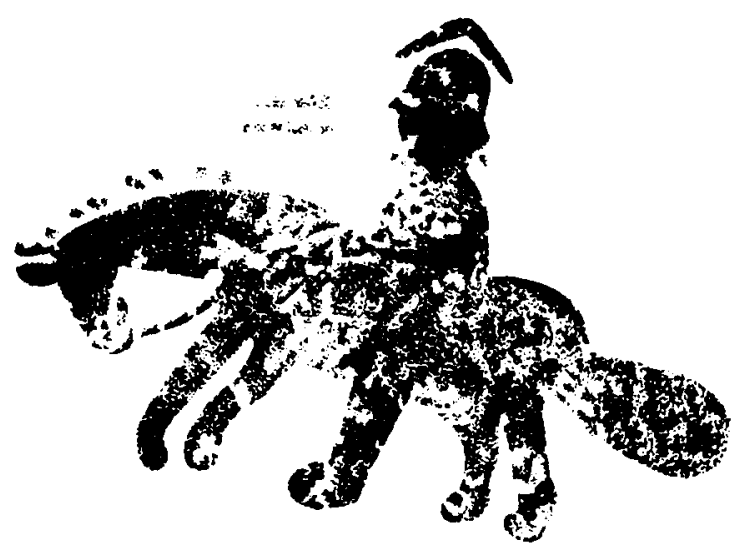

Fig. 13. Jinete del abrigo $X$ del Cingle de La Gasulla (Castellón). (Según E. Ripoll, 1968).

tipo con aparejos, remos y timón. Son de proa alta y popa sobreelevada y, a pesar de la datación que presenta este tipo de arte rupestre, se les ha atribuido una fecha del 1000 al 700 a. de C.", analizando seguidamente cada una de las figuras y llegando a la conclusión de que se trata de naves fenicias, de "época geométrica" o "naves de Tarsis". Compartimos estas opiniones, pero, si sólo tuvieramos en cuenta su contexto figurativo, las embarcaciones de La Laja Alta podrian ser fechadas en el Eneolítico o la plena Edad del Bronce - como ha hecho L. Dams-, aunque los argumentos en favor de una fecha mucho más reciente son convincentes y decisivos. Si se acepta, para los barcos, una fecha convencional en torno al 1000 a. de C., ¿habrá que atribuir la misma datación a las figuras antropomorfas en forma de golondrina o las relacionadas con la forma en "phi", que parecen de la misma mano que las representaciones de las embarcaciones?

Una imagen para la que siempre hemos propugnado una fecha avanzada, es el conocido jinete del abrigo $X$ del Cingle de La Gasulla (Ares del Maestrat, Castellón) (fig. 13). Aunque se trata de una sola figura entre los varios miles que incluye el arte postpaleolítico peninsular, nadie podrá negar que se trata de una representación singular tanto por la forma en que se representa el tema como por los problemas de su fecha y de su estilo. Acerca de la interpretación y datación pensamos que no se ha avanzado mucho desde 1963, en que lo describimos y analizamos. La caballería, entendida como montura de caballos, debe situarse en la Península lbérica hacia los últimos tiempos de segundo milenio a. de $\mathrm{C}$., lo que ya justificamos en dicho estudio del Cingle de La 
Gasulla de aquella fecha. Y, si se acepta dicha atribucion temporal, a ella debería corresponder desde el punto de vista estilistico una figura del momento final de la fase esquemática. En cambio, hecha abstracción de su fecha, el jinete y su montura serían atribuibles, por su estilo, a un momento avanzado del periodo estilizado dinamico de la fase levantina. ¿Hay que hacer mucho más antigua la monta de caballos en nuestra Prehistoria? ¿Se trata, acaso, de una vuelta hacia atras del naturalismo? ¿Puede ser un unicum, obra de un artista que copia o imita la manera de hacer que ve en los abrigos cercanos?

Con todo lo dicho no se agotan, ni mucho menos, los problemas del arte postpaleolitico de la Peninsula Iberica. Esto podria hacer pensar que sabemos poco de estas manifestaciones artisticas, y no es asi. Lo que ocurre es que, al igual que para otras etapas de la historia del arte primitivo, más o menos modernas, de estas o de otras latitudes, las obras artisticas de la Prehistoria encierran secretos culturales y un profundo y enigmático mundo espiritual - un mensaje- que desearíamos conocer mejor. 


\section{BIBLIOGRAFIA}

Acosta, Pilar: La pintura rupestre esquemática en España. Salamanca, 1968.

Almagro Basch, Martín: El covacho con pinturas rupestres de Cogul (Lérida). Lérida, IEI, 1952.

Almagro BASCH, Martin: Las estelas decoradas del suroeste peninsular. Madrid, CSIC, 1966 (Bibliotheca Praehistorica Hispana, VIII).

Almagro Gorbea, Martín: «Representaciones de barcos en el arte rupestre de la Península Ibérica. Aportación a la navegación precolonial desde el Mediterráneo orientalm. (E. RiPOLL, ed.), Actas del Congreso Internacional "El Estrecho de Gibraltar», Ceuta, 1987, Madrid, UNED, 1988. t. I, págs. 389-398 (con toda la bibliografia del tema hasta dicha fecha).

Alonso TeJadA, Anna: El conjunto rupestre de Solana de las Covachas, Nerpio (Albacete). Albacete, IEA, 1980.

ANATI, Emmanuel: Arte preistorica in Anatolia. Capo di Ponte, CCSP, 1972.

BALDELLOU, Vicente: "El arte esquemático y su relación con el levantino en la cuenca alta del rio Vero (Huesca)". (F. JordA, ed.), Actas del Coloquio Internacional sobre Arte Esquemático de la Peninsula Iberica, Salamanca, 1982 (Zephyrus, XXXVI), 1983, págs. 113-115.

- "El arte rupestre post-paleolítico de la zona del rio Vero (Huesca)", Ars Praehistorica, III-IV, 1984-1985, págs. 111-137.

- "Algunas reflexiones sobre el arte rupestre, a través de dos Iragmentos impresos de la cueva de Chaves (Huesca)". Espacio, Tiempo y Forma, serie I (Prehistoria), t. I, 1988 (Homenaje al Prof. Eduardo Ripoll Perelló), págs. 253-267. 
Baptista, A. Martinho: A rocha F-155 e a origem da arte do Vale do Tejo. Oporto, 1981.

- "Arte rupestre do Norte de Portugal: uma perspectiva", Portugalia, 45, 1983-1984, págs. 71-82.

Beltran Martinez, Antonio: Arte rupestre levantino. Zaragoza, Universidad, 1968 (Monografías Arqueológicas, IV) (con suplementos posteriores).

- La cueva del Charco del Agua Amarga y sus pinturas levantinas. Zaragoza, 1970.

Beltran Martinez, Antonio (con la colab. de $V$. Pascual): Las pinturas rupestres prehistóricas de La Sarga (AlCoy). El Salt (Penáguila) y El Calvari (Bocairente). Valencia, 1974 (Trabajos varios del SIP, número 47).

Beltran Martinez, Antonio: De cazadores a pastores. El arte rupestre del Levante español. Madrid, Ed. Encuentro, 1982 (hay ediciones en alemán, francés e inglés).

- «El arte esquemático en la Península Ibérica: orígenes e interrelaciones. Bases para un debate». (F. JoRDA, ed.), Actas del Coloquio Internacional sobre Arte Esquemático de la Península lbérica, Salamanca, 1982 (Zephyrus, XXXVI), 1983, págs. 37-41.

BOSCH GIMPERA, P.: "La chronologie de I'art rupestre seminaturaliste et schematique et la culture mégalithique portugaise", Revista da Facultade de Letras (Lisboa), 9, 1965.

BREUIL, Henri: "Les roches peintes de Minateda", L'Anthropologie, XXX, 1920, págs. 2-50.

- Les peintures rupestres schematiques de la Péninsule Iberique, IV vols., Lagny, Fondation Singer-Polignac, 1933-1935.

Breull, Henri, y BuRkitT, M.: Rock paintings of Southern Andalusia. Oxford, 1929.

Breull, Henri, y Cabre, Juan: "Les peintures rupestres du bassin inférieur de l'Ebre". L'Anthropologie, XX, 1909, págs. 8-20.

CABALlero Klink, A., La pintura rupestre esquemática de la vertiente septentrional de Sierra Morena (provincia de Ciudad Real) y su contexto arqueológico. Ciudad Real, Museo, 1983.

CABre Aguilo, Juan: El arte rupestre en España. Madrid, CIPP, 1915.

Crawford, O. G. S.:The Eye Goddess. Londres, 1958.

DAMS, Lya: Les peintures rupestres du Levant espagnol. Paris, 1984.

EIROA, Jorge Juan: "El Plano del Pulido: un nuevo abrigo con pinturas de estilo levantino en Caspe (Zaragoza)". Ars Praehistorica, III-IV, 1984-1985, págs. 261-269.

EIROA, Jorge Juan, y REY, Josefa: Guia de los petroglifos de Muro. Muro, 1984. 
FORTEA. J.: "Algunas aportaciones a los problemas del arte levantino". Zephyrus. XXV, 1974. pags. 225-257.

FORTEA, J.: «En torno a la cronologia relativa del inicio del arte levantino". Papeles del Laboratorio de Arqueologia de Valencia. 11, 1975. págs. 185-197.

Fortea. J., y Aura Tortosa. E.: "Una escena de vareo en La Sarga (Alcoy). Aportaciones a los problemas del Arte Levantino", Archivo de Prehistoria Levantina. XVII. págs. 97-122.

Garcia Alen. A., y De la Peña Santos. A.: Grabados rupestres de la provincia de Pontevedra. La Coruña, 1980.

Garcia Martinez, M. C.: Arte rupestre en Campo Lameiro. Campo Lameiro, 1973.

GOMES, Mario Varela: "Arte esquemática de Vale do Tejo" (F. Jor$D A$, ed.). Actas del coloquio internacional sobre Arte Esquematico de la Peninsula lbérica. Salamanca, 1982 (Zephyrus. XXXVI), 1983. págs. 277-285.

Gomez BARRERA, Juan A.: La pintura rupestre esquematica de la altimeseta soriana. Soria, 1982.

- "El abrigo de la Peña de los Plantíos, nuevo hallazgo de pinturas esquemáticas en Fuentetoba (Soria)", Ars Praehistorica, III-IV, 19841985, págs. 139-180.

Grande del BRio Ramón: Las pinturas rupestres esquematicas en el centro-oeste de España (Salamanca y Zamora). Ensayo de interpretación del arte esquemático. Salamanca. 1987.

Grazıosı, Paolo: Le pitture preistoriche della grotta di Porto Badisco. Florencia, 1980.

HeRnANDEZ-PACHECO. Eduardo: Las pinturas prehistoricas de las Cuevas de La Arana (Valencia). Evolución del arte rupestre de España. Madrid, 1924 (Memorias CIPP, núm. 34).

- Prehistoria del solar hispano. Madrid, 1959.

Hernandez Perrez, Mauro S., y CeC: "Arte rupestre en el Pais Valenciano. Recientes aportaciones" (F. JORDA, ed.) Actas del coloquio internacional sobre Arte Esquematico de la Península Ibérica. Salamanca, 1982 (Zephyrus. XXXVI), 1983. pags. 63-75.

- "Consideraciones sobre un nuevo tipo de arte rupestre prehistórico", Ars Praehistorica. I, 1982, págs. 197-187.

Hernandez Perez, Mauro S.; Ferrer i Marset, Pere, y Catala Ferrer. Enrique: Arte rupestre en Alicante. Alicante, Fundación Banco Exterior y Banco de Alicante, 1988.

JoRDA CERDA, Francisco: "Notas para una revisión de la cronologia del arte rupestre levantino", Zephyrus, XVII. 1966. págs. 47-76. 
- "La sociedad en el arte rupestre levantino", Papeles del Laboratorio de Arqueologia de Valencia, 11. 1975. págs. 159-184.

JoRge, V. O.; Baptista. A. M., y SAnChes, M. de J.: "A Fraga d'Aia (Paredes de Beira - S. Joâo da Pesqueira)", Trabalhos de Antropologia. XXVIII. 1988. págs. 201-233.

Lopez Payer, M. G.. y SORIA LeRma, M.: "Las pinturas rupestres del Barranco de Doña Dama (La Carolina, Jaén)'s. Ars Praehistorica, IIIIV. 1984-1985. pág. 271-278.

Lopez Payer, M. G. y Soria Lerma, M.: El arte rupestre en Sierra Morena oriental. La Carolina. 1988.

Marti Oliver, Bernat, y Hernandez Perez. Mauro S.: El Neolitic valencia. Art rupestre i cultura material. Valencia, SIP, 1988.

Martin DE. LA CRUz J. C.: "Cerámicas micenicas en Andalucia", Revista de Arqueologia. 78, 1987, págs. 62-64.

Mas CoRnella, Marti: “El conjunto rupestre de Savassona (Tavernoles, Barcelona)". Ars Praehistorica. III-IV, 1984-1985, págs. 181-199.

- «El conjunto rupestre del Tajo de las Figuras. Estado actual de las investigaciones en la Sierra Momia (Cádiz)».(E. Ripoll, ed.). Actas del Congreso Internacional "El Estrecho de Gibraltar". Ceuta, 1987. Madrid. UNED, 1988, t. I. págs. 293-303.

Obermaler. Hugo: “Nouvelles études sur l'art rupestre du Levant espagnol', L'Anthropologie. 47, 1937, págs. 477-498.

Obermaler, Hugo, y Wernert, Paul: Las pinturas rupestres del Barranco de La Valltorta (Castellón). Madrid, 1919 (Memorias CIPP, núm. 23).

Pena Santos, A. de la: "Excavación de un complejo de grabados rupestres en Campo Lameiro (Pontevedra)», Ars Praehistorica, III-IV, 1984-1985, págs. 285-290.

Pericot, L., y Ripoll. E. (editores): Prehistoric Art of the Western Mediterranean and the Sahara. Nueva York, 1968 (actas del simposio del Wartenstein; V.F.P. num. 39).

PinON VARela. Fernando: Las pinturas rupestres de Albarracin (Teruel). Santander. Centro de Altamira, 1982.

Porcar, Juan B.; Obermaler, Hugo, y Breull, Enrique: Excavaciones en la cueva Remigia (Castellón). Madrid. 1935 (Mem. J.S.T.A., núm. 136).

Ripoll Perello, Eduardo: "Para una cronología relativa de las pinturas rupestres del Levante español" (G. FrEUND, ed.), Festschrift für Lothar Zotz. Steinzeitfrage der Alten und Neuen Welt. Bonn, 1960. págs. 457-465.

- Los abrigos pintados de los alrededores de Santolea (Teruel). BarceIona. IPA, 1961 (en inglés, 1967). 
- Pinturas rupestres de La Gasulla (Castellón). Barcelona, IPA, 1963 (en inglés, 1968).

- "Nota acerca de las pinturas rupestres de la Grotta-Scritta en Olmetadu-Cap (Córcega)», Ampurias, XXIX, 1967, págs. 262-267.

- "Cuestiones en torno a la cronología del arte rupestre postpaleolítico en la Península Ibérica». (E. RIPOLL. ed.), Simposio Internacional de Arte Rupestre. Barcelona, 1966, Barcelona, IPA, 1968, págs. 165192.

- "Acerca del problema de los origenes del arte levantino" (E. ANATI, ed.) Actes du Symposium International d'Art Préhistorique. Capo di Ponte, Valcamonica, 1968. Capo di Ponte, CCSP, 1970, págs. 5768.

- "The process of schematisation in the Prehistoric Art of the Iberian Peninsula" (P. J. UCKO, ed.), Form in indigenous Art of Aboriginal Australia and Prehistoric Europe. Canberra, 1977, págs. 418-428.

- «Los grabados rupestres del Puntal del Tio Garrillas (término de Pozondón, Teruel)», Teruel, 66, 1981 (Homenaje a M. Almagro Basch), págs. $147-154$.

- "Cronología y periodización del esquematismo prehistórico en la Península Ibérica» (F. JORDA, ed.), Actas del Coloquio internacional sobre Arte Esquemático de la Peninsula Ibérica, Salamanca, 1982 (Zephyrus, XXXVI), 1983, págs. 27-35.

SORIA Lerma, Miguel, y LOPEz PAyer. Manuel G.: El arte rupestre en el sureste de la Peninsula Ibérica. La Carolina, 1989.

TwohIG, E. Shee: The Megalithic Art of Western Europa. Oxford, 1981.

VAzQUez VARELA, J. M.: "Los petroglifos gallegos" (F. JORDA, ed.), Actas del coloquio internacional sobre Arte Esquematico de la Peninsula Iberica, Salamanca, 1982 (Zephyrus, XXXVI), 1983, págs. 43-51.

VINAs, Ramón, et al.: La Valltorta. Barcelona, Ed. Castell, 1982. 